\title{
Urban sprawl: neighbourhood dissatisfaction and urban preferences. Some evidence from Flanders.
}

\author{
Jonas De Vos ${ }^{\mathrm{a} *}$, Veronique Van Acker ${ }^{\mathrm{a}, \mathrm{b}}$, Frank Witlox ${ }^{\mathrm{a}, \mathrm{c}}$ \\ a Geography Department, Ghent University, Krijgslaan 281 S8, 9000 Ghent, Belgium; ${ }^{b}$ Centre for \\ Urban Studies, University of Amsterdam, Nieuwe Achtergracht 166, 1018 WV Amsterdam, the \\ Netherlands; ' Geography Department, University of Tartu, Vanemuise 46, Tartu 51014, Estonia
}

\section{Abstract}

Early studies suggest that people living in rural neighbourhoods are more satisfied with their residential location than people living in cities. Consequently, most individuals seem to prefer low-density environments to reside in. More recent studies, however, state that rural residents are no more likely to be satisfied with their residential neighbourhood than their urban counterparts. In addition, a considerable, growing part of the population seems to have a clear preference for urban neighbourhoods. The results of our research, conducted in Flanders, Belgium, suggest that urbanites are more satisfied with their neighbourhood than rural residents are. Neighbourhood preferences differ less between urbanites and rural residents. However, there are differences indicating that urbanites have a preference for rural neighbourhoods and rural residents a preference for urban neighbourhoods. In sum, it seems that people, once they have selected their residential location, are not satisfied with the neighbourhood characteristics and tend to develop a preference for a different neighbourhood type. This mismatch can be partly explained by the strongly developed urban sprawl in Flanders, reducing the residential qualities of urban and especially rural environments. Restricting further urban sprawl, with the help of a more active spatial planning policy, seems necessary to increase neighbourhood satisfaction. 


\section{Keywords}

Neighbourhood satisfaction, Neighbourhood preferences, Urban sprawl

\section{Introduction}

A strong preference for rural/suburban living has resulted in an urban sprawl (a low-density expansion of the existing built environment) in most Western countries, especially in the US (Ewing, 1997) but also in most European countries (Patacchini \& Zenou, 2009). Urban sprawl goes hand in hand with two periods of transportation improvements (Brueckner, 2000; Glaeser \& Kahn, 2004; Newman \& Kenworthy, 1996): (i) the introduction of the railway in an anti-urban period at the end of the Industrial Revolution (especially in Europe) and (ii) the period of rising car use after the Second World War (in most Western countries). The Industrial Revolution, starting at the end of the eighteenth century in the United Kingdom, encouraged a lot of people to live in urban areas as factory work replaced many former farm jobs. These small and dense cities, where all destinations were within a reasonable walking distance (Newman \& Kenworthy, 1996), rapidly became overpopulated, and were regarded as the places where diseases and riots developed. In order to solve these social problems, a utopian way of looking at residing in more peaceful, low-density environments with green surroundings emerged (Bruegmann, 2008; Davoudi \& Stead, 2002; Fishman, 1989). Howards' garden city concept (1902), for instance, combined both the advantages of living in a city (proximity of facilities) and the advantages of living in a rural environment (clean air, open spaces). The technological development of passenger trains and trams in industrialised countries (e.g., United Kingdom, Belgium) at the end of the nineteenth century made it possible for factory workers to commute between the countryside and the 
city. This resulted in a first wave of urban sprawl; cities spread outwards generating subcentres around transport nodes such as train and tram stations (Dittmar et al., 2004; Newman, 1992; Newman \& Kenworthy, 1996). A second wave emerged after the Second World War. The technological development of the car, beginning before the war, becomes a dominant form of development after the war. It became the transport technology that shaped the land; the car made it possible to develop in almost every direction. Low-density suburban neighbourhoods, designed to be well-accessible for cars, arose in most Western countries. People were no longer forced to live either near their place of employment or a transit station to transport them there (De Vos \& Witlox, 2013; Gillham, 2002; Glaeser \& Kahn, 2004; Newman \& Kenworthy, 1996). The outer city dispersal of dwellings, and other facilities, was not equal in all countries. Some countries (e.g., The Netherlands, Germany) were able to limit urban sprawl due to active urban planning regulations (Dieleman et al., 1999). In other countries (e.g., Belgium, USA) urban sprawl had free play due to limited amount of spatial planning regulations (Albrechts, 1999; Ewing, 1997). However a lot of people regard rural surroundings still as a peaceful and 'idyll' place to reside in (Halfacree, 1995; Short, 1991), there are indications that the strong preference for a suburban/rural way of living is reducing (Verhetsel \& Witlox, 2006). Partly due to gentrification processes, cities have become more liveable over the past decades, resulting in reurbanisation in some Western cities (Atkinson \& Bridge, 2005; Buzar et al., 2007; Kabisch et al., 2010; Seo, 2002), although other studies indicate that outward suburbanisation is still the dominant pattern (e.g., Williams, 2004). The countryside seems to lose parts of its attraction due to farreaching urban sprawl and (functional) urbanisation, resulting in changes in the rural landscape and spatial structure (Antrop, 2000; Smith, 2007). A significant part of people 
now holds a strong preference for living in highly urbanised environments (Handy et al., 2008; Myers \& Gearin, 2001). Besides, research reveals that people living in low-density suburbs are no more likely to express greater satisfaction with their neighbourhood than those living in the city (Adams, 1992; Farrell et al., 2004; Lovejoy et al., 2010).

This paper analyses neighbourhood preferences and neighbourhood satisfaction of people living in urban and rural neighbourhoods in the strongly urbanised region of Flanders (i.e., the Northern part of Belgium). The remainder of this paper is organised as follows. Section 2 reviews the literature on neighbourhood preferences and neighbourhood satisfaction. Section 3 discusses the Flemish land use pattern while data and methods are discussed in Section 4. Results are presented in Section 5 and discussed in Section 6. Finally, our major conclusions are presented in Section 7.

\section{Neighbourhood satisfaction and preferences}

Neighbourhood satisfaction and neighbourhood preferences are linked with each other. Neighbourhood satisfaction can be regarded as a reflection of people's residential preferences. Individuals preferring a peaceful and quiet neighbourhood probably will not be very satisfied with their neighbourhood if they live in a city centre where there is a lot going on. Neighbourhood satisfaction can be defined as the extent to which needs, concerning the residential neighbourhood, are met (Lovejoy et al., 2010). Neighbourhood preferences can also be affected by neighbourhood satisfaction; residents who are not satisfied with their residential neighbourhood can generate a preference for another type of neighbourhood. In the following literature review we will first discuss neighbourhood satisfaction, of which 
there is extensive research available. Afterwards, the less examined neighbourhood preferences will be tackled.

\subsection{Neighbourhood satisfaction}

Early studies on residential and neighbourhood satisfaction were highly influenced by two general perspectives: a linear-development model and a systemic model (Adams, 1992; Kasarda \& Janowitz, 1974; Parkes et al., 2002). The linear-development model, derived from the work of Wirth (1938) and Tonnies (1963), and influenced by the anti-urban values at the end of the industrial period (Davoudi \& Stead, 2002), states that increasing population size, density and heterogeneity of inhabitants decreases social integration, neighbourhood satisfaction and perceived well-being, and this in a linear fashion. Therefore, small, rural towns characterised by informal social contact and stable, homogeneous populations facilitate strong social networks and good psychological health. Densely populated cities, on the other hand, with a mobile and heterogeneous population and conflicting social norms lead to weak social networks, low involvement in local activities, low neighbourhood satisfaction and poor psychological health (Adams, 1992; Kasarda \& Janowitz, 1974). Hence, the linear-development model predicts that an increase in size and diversity of an area's population will result in people becoming more exploitative in their social relations, individualistic, and alienated from others (Milgram, 1970; Wirth, 1938). According to Milgram (1970), the lack of close interpersonal contact is a function of psychic overload. Contact with a higher percentage of strangers and people from different backgrounds makes the neighbourhood less predictable, more stressful, and less satisfying for residents. Urbanites respond to this overload by ignoring, or at least allocating less time to, individuals 
they meet, reducing participation in local activities and only engaging in exploitative or superficial forms of social interaction. This results in a city life of anonymity and lower physiological health (Adams, 1992; Wirth, 1938).

While the linear-development model mainly focusses on a fixed spatial environment, the systemic model explains neighbourhood satisfaction by using residential turnover as the major explanatory variable. This model, proposed by Kasarda and Janowitz (1974), states that residential mobility operates as a barrier in the development of social bonds and local associational ties. Therefore, a higher degree of neighbourhood stability and length of residence will positively affect local social networks and friendships, neighbourhood satisfaction and the perceived quality of life. This implicates that urbanisation and population density does not affect the local social networks or the neighbourhood satisfaction. People establish strong ties over time and may require numerous interactions in order to feel comfortable with their neighbours. New arrivals to the neighbourhood or a neighbourhood experiencing a high level of turnover results in barriers to the development of strong ties. Residents may be reluctant to form strong emotional attachments toward their neighbours because they know such bonds will not last (Sampson, 1991). Neighbourhood instability and individual mobility also contribute to feelings of isolation, lower satisfaction with the quality of one's life, and a weak sense of self-efficacy (Adams, 1992).

More recent research, however, shows no important differences in neighbourhood satisfaction or perceived well-being of urbanites and suburbanites (Adams, 1992; Farrell et 
al., 2004; Lovejoy et al., 2010). Population density and heterogeneity of inhabitants hardly influences neighbourhood satisfaction. Lovejoy et al. (2010) indicate that typical physical characteristics of urban or suburban neighbourhoods do not have a significant influence on neighbourhood satisfaction. Suburbanites do not seem to derive more neighbourhood satisfaction from typical suburban characteristics (e.g., availability of parking, peaceful environment), nor do urbanites derive more neighbourhood satisfaction from high density or from the proximity of numerous facilities. Perceptions of attractiveness and safety are more important determinants in both residential environments. The difference in neighbourhood satisfaction stems from other aspects, like differences in liveliness and neighbouring (e.g., contact with neighbours, participating in local activities). Urbanites derive more satisfaction from these aspects than suburbanites do; suburbanites seem less interested in these aspects. This indicates a lost sense of community among suburban dwellers, and can explain a light dissatisfaction of suburbanites with their neighbourhood (Lovejoy et al., 2010; Talen, 2001). Liveliness, neighbouring and sense of community seem to play an important role in neighbourhood satisfaction (Farrell et al., 2004).

\subsection{Residential preferences}

Parallel with residential satisfaction, residential preferences evolved from anti-urban preferences into varied preferences (Brower, 1996; Talen, 2001). Due to bad urban living conditions during the Industrial Revolution people created a preference for living in more rural environments (e.g., Davoudi \& Stead, 2002). The development of passenger trains and trams (in the nineteenth century) and the car (in the twentieth century) made it possible for people to live in the countryside but still work in a city (e.g., Newman \& Kenworthy, 1996). 
Nowadays, urban conditions have improved and low-density versus high-density or mixeduse versus single-use developments seem more evenly preferred (Ewing, 1997). Although the biggest group of people, both in Europe and America, still prefer to live in low-density environments, people preferring (high-density and mixed-use) urban neighbourhoods are substantial (Brower, 1996; Brun \& Fagnini, 1994; McDowell, 1997; Van Ham \& Feijten, 2008) and growing (Handy et al., 2008; Myers \& Gearin, 2001). Talen (2001) states that urban sprawl at an advanced stage can lead to an increasing preference for urban neighbourhoods. This evolution in residential preferences seems to play an important role (besides other elements such as decreasing household sizes and delayed child-bearing) in the rise of people living in city centres (reurbanisation) over the past three decades (Buzar et al., 2007; Seo, 2002). Æ Erø (2006) states that tradition is important and that people prefer a residential neighbourhood similar to the neighbourhood they grew up.

\section{The case of Flanders}

In the preceding literature review we have shown how neighbourhood satisfaction and preferences have evolved from anti-urban into more varied attitudes. In this section we will focus on the development of the land use pattern in the Flanders Region, Belgium (surface area: $13,500 \mathrm{~km}^{2}$; inhabitants: 6,300,000; population density: 466 inhabitants $/ \mathrm{km}^{2}$ (http://www.statbel.fgov.be/). Doing so, we investigate whether a diffuse urban field influences the way in which residents perceive their neighbourhood.

Flanders has a widespread land use pattern that has strongly developed since the nineteenth century. At the beginning of the nineteenth century, the Industrial Revolution 
created a lot of employment in Flemish cities; cities which were mostly very compact with well-defined boundaries. Since most employees had neither the time nor the money to commute, many moved from the countryside to the city to live close to their work. In order to prevent a further immigration of labourers to the overpopulated cities, Belgium constructed (starting in 1835) the most densified network of trams and trains of all industrial countries. Together with cheap public transportation passes (starting from 1869) labourers were now able to commute easily between the city and the countryside. Furthermore, cheap government loans enabled a lot of households to build (mostly detached) dwellings with garden on the countryside (e.g., De Decker, 2011; De Vos, 2015; Kesteloot \& De Maesschalk, 2001; Verhetsel et al., 2010). This 'anti-urban' policy, in combination with nearly any spatial planning regulations, resulted in a first wave of urban sprawl; residing far away from the workplace was made possible resulting in suburbanisation and a dispersed land use pattern (e.g., De Vos, 2015; De Vos \& Witlox, 2013). After the Second World War, urban sprawl accelerated even further. The rise of the car made it easier to reside almost everywhere on the countryside, also on places which were difficult to access by train. Suburban neighbourhoods with good car accessibility emerged scattered around the Flemish region. The passive spatial planning policies in Flanders did not hinder the geographical distribution of facilities. In fact, Spatial plans (zoning plans) in the nineteen seventies (i.e., sub-regional plans which are referred to as 'Gewestplannen' ${ }^{1}$ ) designated territories spread around the region as residential area or prospective residential area, based on expected population growth. Furthermore, the socalled 'fill-up' rule, allowing to construct dwellings in non-residential areas between two

\footnotetext{
${ }^{1}$ These plans were mainly developed in order to spatially distribute rising economic activities.
} 
buildings closer than 70 metres from each other, resulted in ribbon development (Bouckaert \& De Waele, 2000). These elements have resulted in a strongly urbanised region where open spaces have become scarce and fragmented over the past decades. Although urban revitalisation policies since the end of the 1990s have improved the general opinion about living in the city (Schuermans et al., 2014; Meeus \& De Decker, 2013), a large part of the available space has already been built up by buildings, infrastructure and all sorts of other activities (Albrechts, 1999). Flanders Region can therefore be considered as a sort of a diffuse city; city and countryside fade into one another; the border is hard to draw (Fig. 1) (De Decker, 2011; De Vos \& Witlox, 2013).

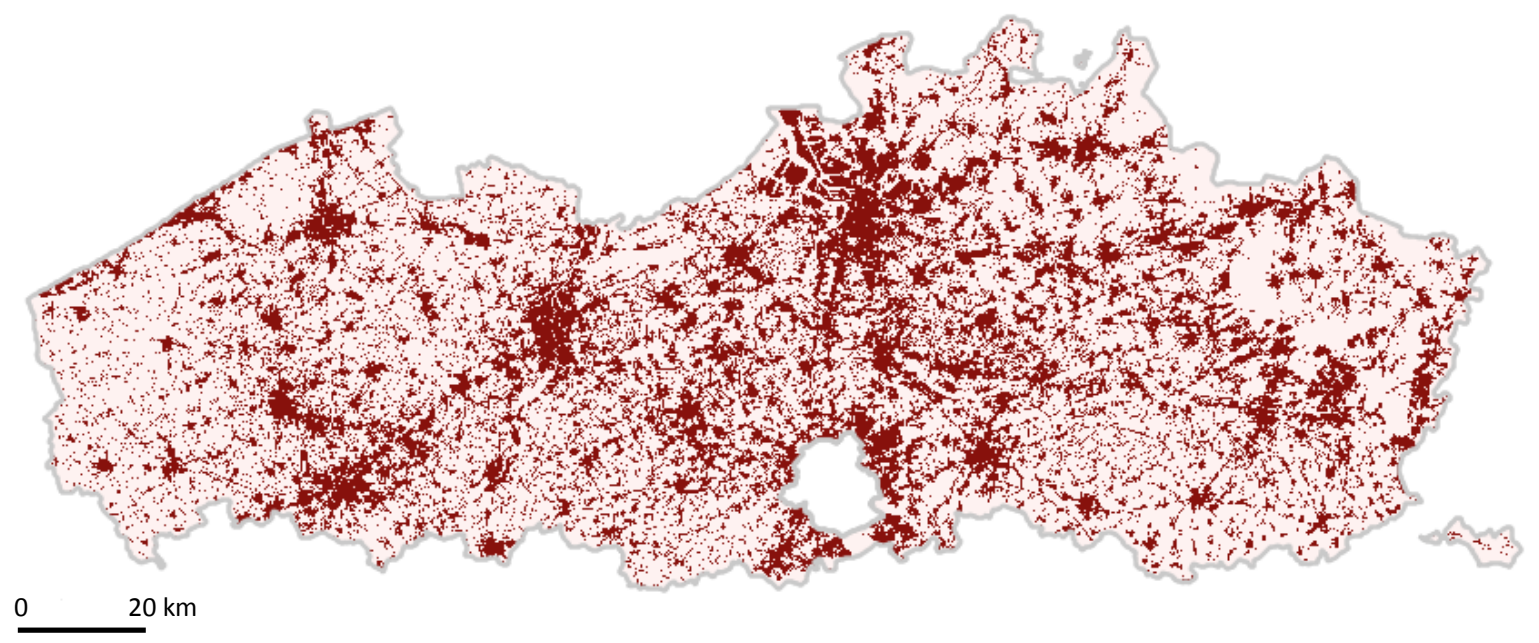

Figure 1. Built-up space (indicated in red) of the Flemish Region in 2010 (Source: http://www.milieurapport.be).

\section{Data and Methods}

\subsection{Data}

For this study we rely on survey data from 2007, collected for a study on mobility, residential location and lifestyles (Van Acker, 2010). As the initial purpose of this extensive 
Internet survey was to analyse the effect of lifestyles on travel behaviour - both directly and indirectly through the residential location choice and car ownership - this survey contains a substantial amount of information on residential satisfaction and residential preferences. In a first stage the survey was distributed among staff members and students of the University of Antwerp and the Faculty of Sciences at Ghent University. In order to obtain a more balanced sample, the survey was, in a second stage, also distributed within the greater region of Ghent (including both urban and rural municipalities). In total, 1,878 respondents completed the survey of which 1,597 were retained after data cleaning. Due to the sampling method, respondents with a university degree, and younger people are - compared to the total Flemish population - overrepresented (for more information on the data, see Van Acker et al., 2011, 2014). Although the sample is consequently not representative of the total population of Flanders, it does enable us to analyse relationships among multiple variables. As our sample size is relatively large and sufficiently diverse, coefficients to characterise specific relationships can be estimated with great confidence (see, for instance, Groves, 1989).

Respondents are subdivided in urban and rural residents, according to the principles of the 'Spatial Structure Plan for Flanders' (Ministerie van de Vlaamse Gemeenschap, 1997). This spatial structure plan divides the Flemish municipalities into categories ranging from big cities to countryside (Fig. 2). We consider respondents residing in big cities to small cities as 'urban residents' and respondents residing outside such urban areas as 'rural residents'. Since we use municipalities ${ }^{2}$ as spatial units instead of neighbourhoods - which would have

\footnotetext{
${ }^{2}$ Flemish municipalities have an average surface area of $43.9 \mathrm{~km}^{2}$
} 
been most ideal - there is a certain loss of information as municipalities can have diverse neighbourhoods. Using the urban-rural subdivision has the advantage of putting forward potential spatial planning interventions in order to increase neighbourhood satisfaction (e.g., the distribution of additional dwellings among urban and rural municipalities). The classification of urban and rural municipalities is of big importance in the 'Spatial Structure Plan for Flanders'. Around $60 \%$ of the Flemings live in urban municipalities, $40 \%$ in rural municipalities (Ministerie van de Vlaamse Gemeenschap, 2011). In the used data sample, only $25.6 \%$ of the respondents reside in rural municipalities; urbanites are consequently overrepresented. Especially people living in the city of Ghent (19.2\% of the respondents) and the city of Antwerp (21.5\% of the respondents) are overrepresented. Respondents living in the eastern and western part of Flanders (i.e., the provinces of Limburg and WestFlanders) are underrepresented. We do acknowledge that the subdivision in urban and rural respondents is crude. A more extensive subdivision of respondents based on their residential location was possible. However, we chose not to do so because the distinction between the various urban and suburban neighbourhoods is often difficult to make as suburban neighbourhoods are rather diverse and predominantly urbanised (Meeus \& De Decker, 2013); while the differences in neighbourhoods between rural municipalities and the group of urban municipalities is most clear. 


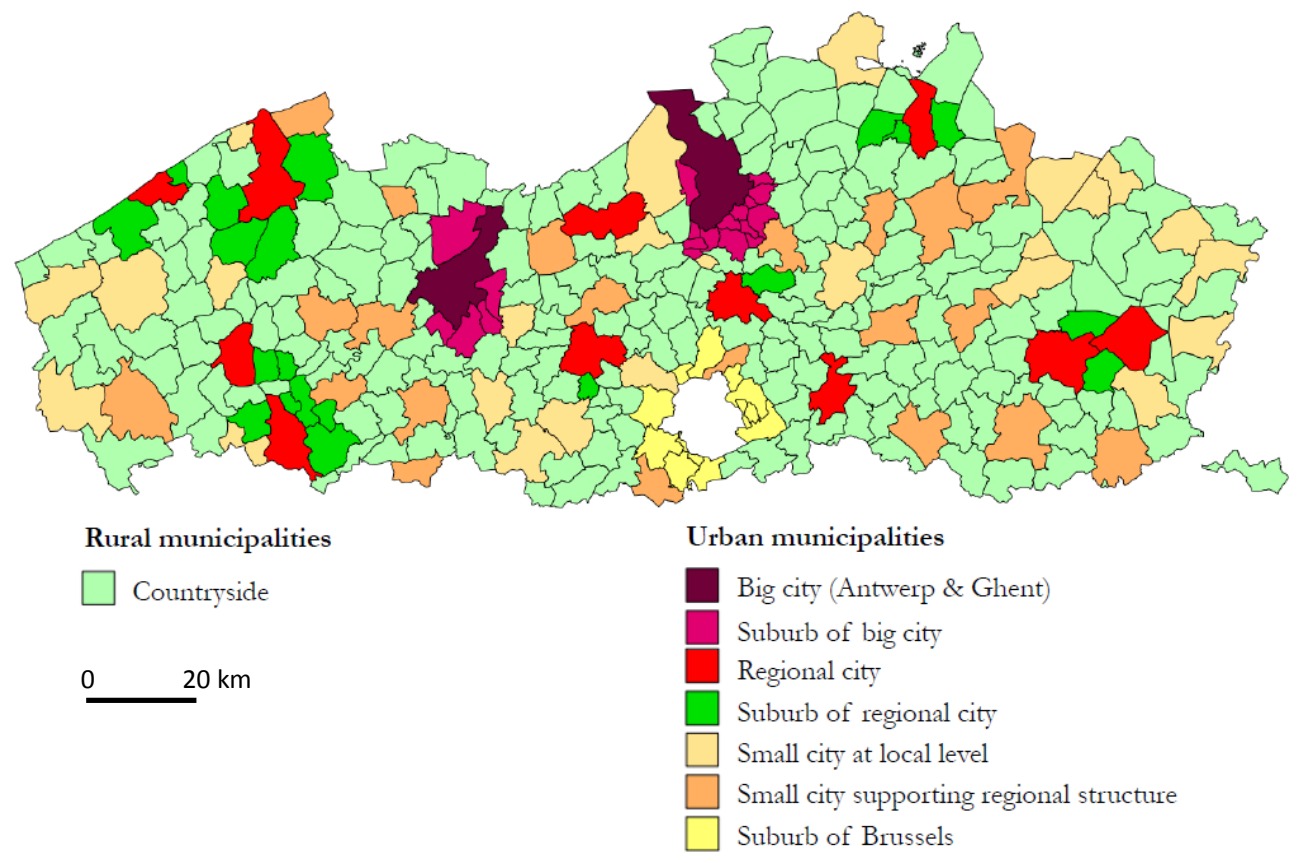

Figure 2. Urban and rural municipalities in Flanders (Source: Ministerie van de Vlaamse Gemeenschap, 1997)

\subsection{Methods}

\subsubsection{Neighbourhood satisfaction}

In order to measure neighbourhood satisfaction, we asked the respondents how satisfied they are with 19 neighbourhood characteristics of their present neighbourhood, i.e., social safety (no vandalism or criminality); traffic safety; presence of bike lanes; presence of sidewalks; sufficient parking place; proximity of public transport; proximity of shops; proximity of leisure activities; proximity of family/friends; proximity of work; peacefulness; presence of green areas; neatness; appearance of buildings; strong interaction with neighbours; frequent interaction with neighbours; composition of residents according to age; composition of residents according to nationality; and distance between dwellings. A five-point Likert scale was presented to them, going from absolutely not satisfied to very satisfied. In order to gain a better insight into which groups of neighbourhood characteristics people are satisfied with, we conducted a factor analysis (principal axis 
factoring; promax rotation). Five factors (based on the scree plot and eigenvalues larger than one) were retained, explaining $60.7 \%$ of the total variance; these factors are Peacefulness and safety; Proximity; Neighbouring; Infrastructure active travel; and Residents' composition (Table 1$).^{3}$

Table 1. Pattern matrix of neighbourhood satisfaction

\begin{tabular}{|c|c|c|c|c|c|}
\hline $\begin{array}{l}\text { How satisfied are you with } \\
\text { aspects of your neighbourhood? } \downarrow\end{array}$ & $\begin{array}{l}\text { Peacefulness } \\
\text { and safety }\end{array}$ & Proximity & Neighbouring & $\begin{array}{l}\text { Infrastructure } \\
\text { active travel }\end{array}$ & $\begin{array}{l}\text { Residents' } \\
\text { composition }\end{array}$ \\
\hline Presence of green areas & 0.85 & & & & \\
\hline Peacefulness & 0.84 & & & & \\
\hline Neatness & 0.82 & & & & \\
\hline Social safety & 0.62 & & & & \\
\hline Appearance of buildings & 0.53 & & & & \\
\hline Traffic safety & 0.49 & & & 0.38 & \\
\hline Distance between dwellings & 0.48 & & & & 0.29 \\
\hline Sufficient parking place & 0.40 & & & & \\
\hline Proximity of leisure activities & & 0.74 & & & \\
\hline Proximity of shops & & 0.73 & & & \\
\hline Proximity of public transport & & 0.56 & & & \\
\hline Proximity of family/friends & & 0.42 & & & \\
\hline Proximity of work & & 0.40 & & & \\
\hline Strong interaction with neighbours & & & 0.83 & & \\
\hline Frequent interaction with neighbours & & & 0.82 & & \\
\hline Presence of sidewalks & & & & 0.74 & \\
\hline Presence of bike lanes & & & & 0.71 & \\
\hline Residents' composition (nationality) & & & & & 0.71 \\
\hline Residents' composition (age) & & & & & 0.61 \\
\hline
\end{tabular}

\subsubsection{Neighbourhood preferences}

In order to measure neighbourhood preferences, we asked the respondents how important they find certain neighbourhood characteristics in the case they had to choose a new residential location. The 19 neighbourhood characteristics used to measure neighbourhood

\footnotetext{
${ }^{3}$ In this research, variables with a factor loading between -0.25 and 0.25 are not retained in the pattern matrices.
} 
satisfaction are also applied to measure neighbourhood preferences. Again, a five-point Likert scale was presented to the respondents, going from absolutely not important to very important. In order to gain a better insight into which groups of neighbourhood characteristics people find important (in the case they have to choose a new neighbourhood), we conducted a second factor analysis (principal axis factoring; promax rotation). This time six factors (based on the scree plot and eigenvalues larger than one) were retained, explaining $62.4 \%$ of total variance: Accessibility; Peacefulness; Proximity; Safety/appearance; Residents' composition and Neighbouring (Table 2).

Table 2. Pattern matrix of neighbourhood preferences

\begin{tabular}{|c|c|c|c|c|c|c|}
\hline $\begin{array}{l}\text { Factor } \rightarrow \\
\text { Suppose you have to choose a } \\
\text { new residential location. Which } \\
\text { aspects are important to you? } \downarrow\end{array}$ & Accessibility & $\begin{array}{l}\text { Peaceful- } \\
\text { ness }\end{array}$ & Proximity & $\begin{array}{c}\text { Safety/ } \\
\text { appearance }\end{array}$ & $\begin{array}{c}\text { Residents' } \\
\text { compo- } \\
\text { sition }\end{array}$ & Neighbouring \\
\hline Presence of sidewalks & 0.87 & & & & & \\
\hline Presence of bike lanes & 0.84 & & & & & \\
\hline Proximity of public transport & 0.36 & & 0.34 & & & \\
\hline Presence of green areas & & 0.94 & & & & \\
\hline Peacefulness & & 0.81 & & & & \\
\hline Proximity of shops & & & 0.74 & & & \\
\hline Proximity of leisure activities & & & 0.68 & & & \\
\hline Proximity of family/friends & & & 0.41 & & & \\
\hline Proximity of work & & & 0.36 & & & \\
\hline Social safety & & & & 0.78 & & \\
\hline Neatness & & 0.28 & & 0.53 & & \\
\hline Sufficient parking place & & & & 0.45 & & \\
\hline Traffic safety & 0.40 & & & 0.42 & & \\
\hline $\begin{array}{l}\text { Residents' composition } \\
\text { (nationality) }\end{array}$ & & & & & 0.74 & \\
\hline Residents' composition (age) & & & & & 0.71 & \\
\hline Distance between dwellings & & 0.34 & & & 0.35 & \\
\hline $\begin{array}{l}\text { Frequent interaction with } \\
\text { neighbours }\end{array}$ & & & & & & 0.81 \\
\hline $\begin{array}{l}\text { Strong interaction with } \\
\text { neighbours }\end{array}$ & & & & & & 0.71 \\
\hline
\end{tabular}




\subsubsection{Socio-economic factors}

Not only the residential neighbourhood, but also socio-economic factors can influence neighbourhood satisfaction and neighbourhood preferences. However, results from previous studies show that there exists disagreement in the way that, for instance, age, gender, and household composition affect neighbourhood satisfaction (Adams, 1992; Lovejoy et al., 2010; Parkes et al., 2002). There seems to be more unity between researchers in the way that socio-economic factors influence neighbourhood preferences (Lovejoy et al., 2010). Most authors state that, for instance, dual-earner households with children and a high income mostly prefer living in low-density environments (Bhat \& Guo, 2007; Talen, 2001). In order to investigate the influence of socio-economic factors on neighbourhood satisfaction and preferences, we included six socio-economic factors: Age (years); Gender (0 $=$ male; $1=$ female); Personal income (subdivided in seven categories, ranging from 0 to $+3000 €$, with an interval of $500 €$ ); Education (subdivided in thirteen categories, ranging from no education to post-university education); Number of children in household and household car ownership.

\subsubsection{Lifestyles}

Lifestyle is a rather vague concept with many meanings (Kipnis, 2004). A lifestyle can be considered as a pattern of behaviours indicating the social position of individuals. However, a lifestyle is more than just observable behaviour (often referred to as lifestyle expression). It also includes opinions and motivations, including belief, interests and attitudes (often referred to as the underlying factors of a lifestyle) (Bourdieu, 1984; Munters, 1992; Weber, 1972). According to Heijs et al. (2009), lifestyles refer to elements varying from behaviour 
(e.g., choice, use and consuption), behavioural domains (e.g., work, household) and factors influencing behaviour (e.g., intentions, preferences and values). The importance of lifestyles has increased in the last decades due to the rise of prosperity and individualisation and the decrease of social control (e.g., Kipnis, 2004).

Previous research on neighbourhood satisfaction and preferences only included lifestyles to a certain degree. These studies state that individuals with varying lifestyles seem to have different preferences concerning their residential location (Hesse \& Scheiner, 2009; Van Acker et al., 2011). According to Brun and Fagnini (1994), individuals or couples who are socially active often prefer to live in city centres where there are a lot of cultural opportunities, while individuals who organise their life around their family prefer to live in suburbs. Pisman et al. (2011) and Van Acker et al. (2011) - performing their study in Flanders - state that people having various lifestyles do not only have different residential preferences, but also actually live in different neighbourhoods. People feeling safe in their neighbourhood and regarding economic status as an important value reside more often in suburban neighbourhoods compared to urban neighbourhoods (Pisman et al., 2011), while Van Acker et al. (2011) indicates that culture lovers tend to live in urban neighbourhoods while people with an active lifestyle live more in rural neighbourhoods. Furthermore, a certain homogeneity of lifestyles in a matching residential situation may improve residential satisfaction (Heijs et al., 2009). 
Van Acker et al. (2011), using the same survey, subdivided the respondents into five lifestyles based on the organisation of holidays, literary interests and leisure activities performing exploratory factor analysis:

- Culture lovers: lifestyle related to cultural literature and cultural holidays. Culture lovers are socially engaged.

- Friends and Trends: lifestyle in which a person's social network is more oriented toward friends than toward family.

- Home-oriented but active family: lifestyle related to family and respondents' home, but also to different kinds of sports and self-organised, active holidays.

- Low-budget and active/creative: Combination of an active lifestyle with a low-budget lifestyle; also characterised by creativity.

- Home-oriented traditional family: Lifestyle focused on family and respondents' home, but also on traditional, mostly indoor, activities.

\subsubsection{Travel mode preference}

Travel mode preference can have an important influence on the residential location choice. People can self-select a certain neighbourhood in order to travel with their preferred travel mode (residential self-selection). A car lover, for instance, will mostly prefer living in rural environments due to limited parking problems and traffic congestion (e.g., Handy et al., 2005; Bhat \& Guo, 2007; van Wee, 2009). De Vos et al. (2012), using the same survey, subdivided the respondents, based on second-order exploratory factor analysis on travelrelated attitudes, in the two following categories of travel mode preference: Pro car alternatives and Pro car (for more detail, see Appendix). 


\section{Results}

Table 3 indicates that urbanites and especially rural residents are rather dissatisfied with their neighbourhood. The mean values of neighbourhood satisfaction are situated between not satisfied (value 2) and neutral (value 3). Mean values of neighbourhood preferences are situated between not important (value 2) and neutral (value 3), indicating that respondents do not attach very much importance to neighbourhood characteristics. Urbanites are more satisfied with most neighbourhood characteristics than rural residents. However, neighbourhood satisfaction is not the same for all neighbourhood characteristics. Rural residents, for instance, are - in comparison with urbanites - more satisfied with the proximity of shops, leisure activities, public transport and work. Neighbourhood preferences differ less between urbanites and rural residents. Only 10 of the 19 preferences of neighbourhood characteristics differ between urbanites and rural residents (at $p<0.05$ ). The respondents' mean values of neighbourhood satisfaction and preference positively correlate with each other $(R=0.11 ; p=0.00)$; individuals who are satisfied with a certain characteristic will mostly attach a lot of importance to that particular characteristic and vice versa. Respondents also seem to attach quite a lot of importance to non-physical characteristics, like frequent contact with neighbours and the residents' composition. Safety aspects on the other hand, seem less important. 
Table 3. Respondents' scores on neighbourhood satisfaction and preferences

\begin{tabular}{|c|c|c|c|c|c|c|}
\hline & \multicolumn{3}{|c|}{ Neighbourhood satisfaction } & \multicolumn{3}{|c|}{ Neighbourhood preferences } \\
\hline & urban & rural & t-Test & Urban & rural & $\mathrm{t}$-Test \\
\hline Social safety & 1.87 & 1.50 & $*$ & 1.71 & 1.64 & $*$ \\
\hline Traffic safety & 2.32 & 2.00 & $*$ & 1.88 & 1.80 & $*$ \\
\hline Presence of bike lanes & 2.78 & 2.50 & $*$ & 2.06 & 2.00 & \\
\hline Presence of sidewalks & 2.18 & 2.34 & $*$ & 1.89 & 2.03 & $*$ \\
\hline Sufficient parking place & 2.48 & 2.03 & $*$ & 2.36 & 2.19 & $*$ \\
\hline Proximity of public transport & 1.65 & 2.16 & $*$ & 1.82 & 1.96 & $*$ \\
\hline Proximity of shops & 1.85 & 2.20 & $*$ & 2.14 & 2.33 & $*$ \\
\hline Proximity of leisure activities & 2.10 & 2.40 & $*$ & 2.32 & 2.39 & \\
\hline Proximity of family/friends & 2.15 & 2.15 & & 2.41 & 2.33 & \\
\hline Proximity of work & 2.24 & 2.88 & $*$ & 2.20 & 2.30 & \\
\hline Peacefulness & 2.29 & 1.80 & $*$ & 1.84 & 1.61 & $*$ \\
\hline Presence of green areas & 2.43 & 1.71 & $*$ & 1.86 & 1.61 & $*$ \\
\hline Neatness & 2.29 & 1.72 & $*$ & 1.89 & 1.80 & \\
\hline Appearance of buildings & 2.35 & 2.01 & $*$ & 2.41 & 2.47 & \\
\hline Strong interaction with neighbours & 2.31 & 2.05 & $*$ & 2.32 & 2.24 & \\
\hline Frequent interaction with neighbours & 2.53 & 2.26 & $*$ & 3.10 & 2.95 & $*$ \\
\hline Residents' composition (age) & 2.48 & 2.41 & & 3.42 & 3.41 & \\
\hline Residents' composition (nationality) & 2.37 & 2.10 & $*$ & 3.47 & 3.44 & \\
\hline Distance between dwellings & 2.46 & 1.96 & $*$ & 2.88 & 2.50 & $*$ \\
\hline Mean & 2.25 & 2.10 & $*$ & 2.32 & 2.26 & $*$ \\
\hline
\end{tabular}

* A significant difference in mean between urbanites and rural residents at $p<0.05$

\subsection{Neighbourhood satisfaction}

In order to investigate which neighbourhood characteristics urbanites and rural residents are more satisfied with, we compared the means (two sample t-test) of the factor scores of the five factors for urban and rural residents (Table 4). Urbanites are, in general, more satisfied with their neighbourhood than rural residents. They are more satisfied with peacefulness and safety, neighbouring and the composition of the neighbourhood's residents. This contrasts with the results of Pisman et al. (2011), stating that urbanites in Ghent feel less safe than people living in more suburban neighbourhoods. However, these results are in line with Meeus and De Decker (2013) and Schuermans et al. (2014). Their studies in the region of Ghent indicate that rural residents feel less safe in their 
neighbourhoods, seem to have more problems with inhabitants of diverse cultural and racial background (although this group is smaller in rural neighbourhoods than in urban neighbourhoods) and are rather dissatisfied with the limited interaction with neighbours. It also seems that safety issues are related with the composition of the neighbourhoods. Rural residents feel less safe partly due to an increasing diversity of inhabitants, while urban residents seem less bothered with this diversity. Results also suggest that residential turnover - which is mostly higher in urban neighbourhoods - does not seem to have a negative effect on (the satisfaction with) interaction with neighbours.

Rural residents, on the other hand, are more satisfied with the proximity of shops, leisure activities, etc. Urbanites and rural residents seem equally satisfied with the infrastructure for active travel in their neighbourhood. These results are quite surprising. Residents seem satisfied with typical neighbourhood characteristics of a different type of neighbourhood. We would have expected that urbanites are satisfied with the proximity of numerous facilities, since most of these facilities are present within short distance. Rural residents, on the other hand, are expected to be more satisfied with the presence of green areas and peacefulness, aspects which are more present in rural environments. It seems however, that residents did not find what they are looking for in their neighbourhood, resulting in a low satisfaction on these aspects. These results also suggest that urban residents are especially more satisfied with non-physical characteristics (e.g., neighbouring and residents' composition); while the satisfaction with physical characteristics (proximity of facilities and the presence of sidewalks, bike lanes and sufficient parking place) is less determined by the type of residential neighbourhood. 
Table 4. Two sample t-tests of the factor scores of neighbourhood satisfaction

\begin{tabular}{lccccccc}
\hline & \multicolumn{3}{c}{ Urban } & \multicolumn{3}{c}{ Rural } \\
& Min/max & Mean & s.d. & Min/max & Mean & s.d. & t-Test \\
\hline Peacefulness and safety & $-1.7 / 3.3$ & 0.17 & 0.95 & $-1.7 / 1.6$ & -0.49 & 0.74 & $*$ \\
Proximity & $-1.7 / 3.8$ & -0.12 & 0.83 & $-1.5 / 3.1$ & 0.35 & 0.92 & $*$ \\
Neighbouring & $-1.9 / 3.4$ & 0.07 & 0.91 & $-1.9 / 3.4$ & -0.21 & 0.89 & $*$ \\
Infrastructure active travel & $-1.8 / 2.8$ & 0.01 & 0.84 & $-1.7 / 2.8$ & -0.03 & 0.94 & \\
Residents' composition & $-2.5 / 4.5$ & 0.06 & 0.85 & $-2.5 / 1.7$ & -0.19 & 0.74 & $*$ \\
\hline
\end{tabular}

${ }^{*}$ A significant difference in mean between urban and rural respondents at $p<0.05$

There are some clear variances in the nature of different neighbourhood characteristics. An important differentiation can be made between physical attributes (e.g., presence of sidewalks/bike lanes and proximity of facilities) and non-physical characteristics (interaction with neighbours and residents' composition). When conducting a second-order factor analysis (principal axis factoring; promax rotation) on the (first-order) factors of neighbourhood satisfaction, we can see a clear differentiation between satisfaction with physical and non-physical neighbourhood characteristics. Two factors (based on scree plot and eigenvalues larger than one), explaining $67.0 \%$ of the variance, were retained: i.e. Nonphysical aspects and Physical aspects (Table 5). The first- and second-order factor analysis explain $40.7 \%(60.7 \% * 67.0 \%)$ of the total variance, which is rather high in comparison with other second-order factor analyses (De Vos et al., 2012; Van Acker, 2010). Respondents with a positive score on the first factor are satisfied with non-physical aspects of their neighbourhood, such as interaction with neighbours and the composition of the residents. Respondents with a positive score on the second factor are satisfied with physical aspects, such as infrastructure for active travel and the proximity of facilities. 
Table 5. Pattern matrix of the second-order factor analysis of neighbourhood satisfaction

\begin{tabular}{lcc}
\hline \multicolumn{1}{c}{ Second-order factor $\rightarrow$} & Non-physical aspects & Physical aspects \\
First-order factor $\downarrow$ & 0.84 \\
\hline Residents composition & 0.68 \\
Neighbouring & 0.63 & 0.97 \\
Peacefulness and safety & & 0.27 \\
\hline Infrastructure active travel & & \\
proximity & & \\
\hline
\end{tabular}

In order to see which factors (socio-economic factors, lifestyles, travel preferences and neighbourhood type) influence these two types of neighbourhood satisfaction, we conduct two multiple linear regressions (Table 6$).{ }^{4}$ Although both regressions are significant (at $p<$ 0.05 ), and therefore useful, the values of $R^{2}$ (respectively 0.16 and 0.08 ) are rather low. This means that variance in neighbourhood satisfaction is to a large extent explained by variables which were not included in the analysis.

In general, women, highly-educated people, people with a low-budget lifestyle and urbanites are more satisfied with their neighbourhood than other people. People with a high household car ownership and living in rural neighbourhoods will mostly be less satisfied. There are however, differences in the satisfaction between physical and nonphysical neighbourhood characteristics. For instance, individuals with a large number of children in their household are more likely to be satisfied with physical characteristics but less with non-physical characteristics compared to others. Highly educated people, people with a home-oriented traditional family lifestyle and urbanites are more satisfied with the

\footnotetext{
4 The variables 'personal income' and 'education' are ordinal variables. However, in the linear regressions conducted in this study we treat them as though they are continuous (numeral). This is a reasonable choice since the number of categories of 'education' is large (i.e., thirteen) and the seven categories of 'personal income' have a constant interval (i.e., 500 euro) (Torra et al., 2006).
} 
interaction with neighbours and the composition of the residents than other people. Household car ownership, living in rural neighbourhoods and a home-oriented but active family lifestyle have a negative influence on this type of satisfaction. The fact that rural residents are less satisfied with neighbouring factors suggests that they experience a lost sense of community and are less attached to their neighbourhood than urbanites. This is in line with Meeus and De Decker (2013), stating that - in Flanders - the sense of community is now stronger in urban neighbourhoods compared to more rural neighbourhoods, while this was the other way around some decades ago. Women and people with a low-budget lifestyle are mostly satisfied with the physical characteristics of the neighbourhood. People who prefer travelling by car alternatives and people with a home-oriented traditional family lifestyle are mostly less satisfied with physical neighbourhood characteristics.

Satisfaction with the residential neighbourhood according to socio-economic factors, lifestyles or travel preferences could, however, differ according to whether respondents live in urban or rural neighbourhoods. For the satisfaction with non-physical aspects of the neighbourhood we only found interaction effects $(p<0.05)$ between the 'home-oriented traditional family' lifestyle and the neighbourhood type. This lifestyle only (positively) affects this type of satisfaction for urban residents; while the effect of this lifestyle for rural residents is limited. For the satisfaction with physical aspects of the neighbourhood interaction effects exist between gender and the residential neighbourhood and between household car ownership and the residential neighbourhood. Men are more satisfied with physical aspects of the neighbourhood when living in rural neighbourhoods, while women are more satisfied with physical aspects when living in urban neighbourhoods. Finally, 
respondents living in a household with a high car possession are more satisfied with physical aspects of the neighbourhood when living in a rural area; while a low household car possession results in a higher satisfaction with physical characteristics when living in an urban neighbourhood.

Table 6. Determinants of residential satisfaction

\begin{tabular}{|c|c|c|c|c|c|c|}
\hline & \multicolumn{3}{|c|}{ Non-physical aspects } & \multicolumn{3}{|c|}{ Physical aspects } \\
\hline & Coef. & t-stat & & Coef. & t-stat. & \\
\hline \multicolumn{7}{|l|}{ Socio-economic factors } \\
\hline Age & 0.005 & 1.38 & & 0.001 & 0.37 & \\
\hline Gender & 0.009 & 0.13 & & 0.207 & 2.53 & * \# \\
\hline Personal income & -0.030 & -0.90 & & -0.025 & -0.60 & \\
\hline Education & 0.037 & 2.19 & $*$ & 0.019 & 0.95 & \\
\hline Children in household & -0.081 & -2.79 & $*$ & 0.083 & 2.37 & $*$ \\
\hline Household car ownership & -0.149 & -4.07 & $*$ & -0.004 & -0.10 & $\#$ \\
\hline \multicolumn{7}{|l|}{ lifestyle } \\
\hline Culture lover & 0.000 & 0.00 & & 0.059 & 1.37 & \\
\hline Friends-and-trends & 0.051 & 1.41 & & -0.048 & -1.11 & \\
\hline Home-oriented but active family & -0.072 & -2.16 & $*$ & 0.027 & 0.67 & \\
\hline Low-budget and active/creative & 0.045 & 1.33 & & 0.084 & 2.04 & $*$ \\
\hline Home-oriented traditional family & 0.118 & 2.66 & * \# & -0.129 & -2.42 & $*$ \\
\hline \multicolumn{7}{|l|}{ Travel preference } \\
\hline Pro car alternatives & 0.007 & 0.19 & & -0.083 & -1.94 & \\
\hline Pro car & -0.040 & -1.09 & & 0.035 & 0.79 & \\
\hline \multicolumn{7}{|l|}{ Neighbourhood type } \\
\hline Actual residential neighbourhood & 0.220 & 3.03 & $*$ & 0.021 & 0.24 & \\
\hline$R^{2}$ & \multicolumn{3}{|c|}{$0.16^{*}$} & \multicolumn{2}{|c|}{$0.08 *$} & \\
\hline
\end{tabular}

* significant at $p<0.05$

\# interaction effects with neighbourhood type $(p<0.05)$

\subsection{Neighbourhood preferences}

By comparing the means (two sample t-test) of the factor scores of the six neighbourhood preference factors for urban and rural residents we investigated which neighbourhood characteristics urbanites and rural residents find important (Table 7). Although differences 
between urbanites and rural residents in neighbourhood preferences are smaller than for neighbourhood satisfaction, there are still some significant differences noticeable. Urbanites prefer a peaceful and safe neighbourhood. They also find the residents' composition and neighbouring aspects more important than rural residents. ${ }^{5}$ Rural residents attach more importance to proximity. So respondents tend to find typical neighbourhood characteristics of other types of neighbourhoods more important than typical characteristics of their actual neighbourhood. This suggests that most people are not really satisfied with their neighbourhood. In the case they had to choose a new neighbourhood, they will attach more importance to aspects which are not, or only limited, available in their present neighbourhood.

Table 7. Two sample t-tests of the factor scores of neighbourhood preferences

\begin{tabular}{lccccccc}
\hline & \multicolumn{3}{c}{ Urban } & \multicolumn{3}{c}{ Rural } \\
& Min/max & Mean & s.d. & Min/max & Mean & s.d. & t-Test \\
\hline Accessibility & $-1.6 / 3.9$ & -0.01 & 0.91 & $-1.6 / 4.4$ & 0.03 & 0.97 & \\
Peacefulness & $-1.4 / 4.3$ & 0.09 & 0.96 & $-1.4 / 2.8$ & -0.26 & 0.81 & $*$ \\
Proximity & $-2.2 / 3.5$ & -0.04 & 0.82 & $-1.9 / 3.9$ & 0.12 & 0.96 & $*$ \\
Safety/appearance & $-1.9 / 3.9$ & 0.04 & 0.88 & $-1.8 / 3.4$ & -0.11 & 0.84 & $*$ \\
Residents' composition & $-3.0 / 2.1$ & 0.03 & 0.85 & $-2.8 / 2.0$ & -0.07 & 0.87 & $*$ \\
Neighbouring & $-2.2 / 2.9$ & 0.04 & 0.87 & $-2.1 / 2.8$ & -0.12 & 0.89 & $*$ \\
\hline
\end{tabular}

${ }^{*}$ A significant difference in mean between urban and rural respondents at $p<0.05$

The six factors of neighbourhood preferences are related to certain neighbourhood characteristics. However, they are not unambiguously related with a preference toward an urban or rural neighbourhood. In order to obtain factors which unambiguously reflect

\footnotetext{
${ }^{5}$ The fact that urbanites attach more importance to the residents' composition seems to contradict with results from Table 3, where no significant differences in neighbourhood preferences regarding the residents' composition between urbanites and rural respondents were detected. These differences are a result of the 'residents' composition' factor, which is not only affected by the two variables referring to residents' composition, but also by other variables (e.g., distance between dwellings).
} 
preferences for a certain type of neighbourhood, we factor analysed the obtained factors. This second-order factor analysis results in two second-order factors which are related with two neighbourhood preferences: i.e., Pro Rural and Pro Urban (Table 8). The two secondorder factors explain $61.5 \%$ of the variance. Interpretation and eigenvalues larger than one are the most important determinants for the number of factors (principal axis factoring; promax rotation). The first and second-order factor analysis explain $38.4 \%$ (62.4\% * 61.5\%) of the total variance. However this is rather high for a second-order factor analysis, it indicates that other elements which are not included into the analysis influence neighbourhood preferences.

Table 8. Pattern matrix of the second-order factor analysis of neighbourhood preferences

\begin{tabular}{lcc}
\hline & Second order factor $\rightarrow$ & Pro urban \\
First order factor $\downarrow$ & Pro rural & \\
\hline Peacefulness & 0.81 & \\
Safety / appearance & 0.79 & 0.35 \\
Neighbouring & 0.41 & \\
Residents composition & 0.41 & 0.80 \\
\hline Proximity & & 0.37 \\
Accessibility & 0.30 & \\
\hline
\end{tabular}

Respondents with a positive score on the first factor (Pro rural) prefer a peaceful and safe neighbourhood. They also attach importance to the appearance of the neighbourhood and to the residents' composition. Respondents with a positive score on the second factor (Pro urban) prefer a neighbourhood with shops, leisure activities, and other amenities nearby. Neighbouring and accessibility seem to be equally important for respondents with a positive score on the first factor and respondents with a positive score on the second factor. 
In the following part we examine which aspects (socio-economic factors; lifestyles, travel preference and the actual residential neighbourhood) affect both types of neighbourhood preferences most. To this end we conduct two multiple linear regressions (Table 9), which are both significant $\left(p<0.05 ; R^{2}\right.$ is respectively 0.19 and 0.15$)$. Socio-economic factors have an important role on neighbourhood preferences. Men and highly educated people will mostly prefer rural residential neighbourhoods. Women, persons with a high income and people living in a household with a high car ownership have a preference for urban neighbourhoods. Neighbourhood preferences do not seem to differ very much according to age and the number of children in household. However, the coefficients in Table 9 indicate that older people and people living in a household with many children do not seem to find neighbourhood characteristics that important. Lifestyles (except low-budget and active/creative) also seem to affect neighbourhood preferences. Individuals with a culture lover, friends-and-trends and home-oriented traditional family lifestyle seem to prefer rural neighbourhoods. Individuals with a home-oriented but active family lifestyle mostly prefer urban neighbourhoods. Car loving persons prefer urban neighbourhoods and persons who prefer travelling by car alternatives (public transport, cycling or walking) have a preference for rural residential neighbourhoods. Preceding results are quite surprising. We could have expected, for instance, that a car loving person with a high personal income and a homeoriented but active family lifestyle would prefer a rural environment. However, our results suggest the opposite. This is also being emphasised by the neighbourhood preferences of urbanites and rural residents. Although not statistically significant, urbanites have a slight preference for rural neighbourhoods, while rural residents slightly prefer urban neighbourhoods. Neighbourhood preferences according to socio-economic factors, lifestyles 
or travel preferences could also differ according to whether respondents live in urban or rural neighbourhoods. However, no significant $(p<0.05)$ interaction effects were found between these variables and the neighbourhood type for neighbourhood preferences.

Table 9. Determinants of residential preferences

\begin{tabular}{|c|c|c|c|c|c|c|}
\hline & \multicolumn{2}{|c|}{ Pro rural } & & \multicolumn{3}{|c|}{ Pro urban } \\
\hline & Coef. & t-stat. & & Coef. & t-stat. & \\
\hline \multicolumn{7}{|l|}{ Socio-economic factors } \\
\hline Age & -0.010 & -2.96 & $*$ & -0.009 & -2.97 & * \\
\hline Gender & -0.203 & -3.02 & $*$ & -0.089 & -1.39 & \\
\hline Personal income & -0.011 & -0.32 & & 0.065 & 2.06 & * \\
\hline Education & 0.053 & 3.17 & $*$ & 0.015 & 0.97 & \\
\hline Children in household & -0.082 & -2.87 & $*$ & -0.070 & -2.57 & * \\
\hline Household car ownership & -0.048 & -1.33 & $*$ & 0.035 & 1.01 & \\
\hline \multicolumn{7}{|l|}{ lifestyle } \\
\hline Culture lover & 0.086 & 2.41 & $*$ & -0.013 & -0.37 & \\
\hline Friends-and-trends & 0.072 & 2.03 & $*$ & -0.030 & -0.89 & \\
\hline Home-oriented but active family & -0.206 & -6.32 & $*$ & -0.049 & -1.58 & \\
\hline Low-budget and active/creative & 0.014 & 0.42 & & 0.052 & 1.61 & \\
\hline Home-oriented traditional family & 0.005 & 0.12 & & -0.213 & -5.09 & * \\
\hline \multicolumn{7}{|l|}{ Travel preference } \\
\hline Pro car alternatives & 0.065 & 1.86 & & -0.084 & -2.51 & * \\
\hline Pro car & -0.030 & -0.82 & & 0.181 & 5.20 & * \\
\hline \multicolumn{7}{|l|}{ Neighbourhood type } \\
\hline Actual residential neighbourhood & 0.025 & 0.35 & & -0.104 & -1.54 & \\
\hline$R^{2}$ & \multicolumn{3}{|c|}{$0.19 *$} & \multicolumn{3}{|c|}{$0.15^{*}$} \\
\hline
\end{tabular}

* significant at $p<0.05$

\section{Discussion}

In this section we will try to explain the results obtained in Section 5. However, we have to be careful with conclusions as (i) the used data is quantitative - and we therefore do not really know why respondents prefer certain neighbourhood characteristics and why they are (dis)satisfied with them - and (ii) the respondents are not representative for the total population of Flanders. 
Our results suggest that urbanites are more satisfied with their neighbourhood than rural residents. However, not only the physical neighbourhood characteristics explain this difference, but also neighbouring factors (i.e. social interaction with neighbours). Urbanites are more satisfied with social interaction with their neighbours and the residents' composition compared to rural residents. Rural residents, on the other hand, are more satisfied with the proximity of amenities. Besides a larger overall satisfaction of urbanites (compared to rural residents), there is also another striking result. Respondents tend to be more satisfied with typical neighbourhood characteristics of different types of neighbourhoods; urbanites are more satisfied with peacefulness and safety, while rural residents are more satisfied with the proximity of facilities. These results are not in line with an earlier study in the Ghent region, stating that suburban respondents are generally more satisfied with their residential environment compared to their urban counterparts (Pisman et al., 2011). According to this study there still exists a preference for living in a detached dwelling in a purely residential area. However, this study did not include rural residents.

It seems logical that people choose a neighbourhood in order to satisfy certain needs. For instance, an individual who desires to live nearby open spaces in a peaceful and green surrounding will mostly choose a dwelling in a rural neighbourhood. However, in Flanders, it seems that the chosen neighbourhood is mostly not able to fulfil these needs. Therefore, they are not satisfied with the typical aspects of that neighbourhood. In the case these individuals would have to choose a new residential location, they will consequently attach more importance to typical neighbourhood characteristics of different types of neighbourhoods. However, in the case they would relocate to another type of 
neighbourhood, they would probably (at least after a certain period of time) be dissatisfied again, since the typical neighbourhood aspects of the chosen neighbourhood are probably again not ideally available.

These results can be partly explained by the land use pattern of the Flanders Region, where urban sprawl has always had free play. This results, however, in cities and especially countryside which are losing their typical qualities as residential location. Since most facilities are spread around the whole region, proximity decreases for urbanites. However, residential qualities diminish most for rural residents. The proximity of open and green spaces (which are important determinants of neighbourhood satisfaction (Arnberger \& Eder, 2011; Ellis et al., 2006; Kearney, 2006; Lee et al., 2008)) has decreased rapidly; noise and light nuisance are present almost everywhere. Urban sprawl, the growth of infrastructure and functional urbanisation have resulted in changes in the rural landscape and spatial structure (Antrop, 2000; Smith, 2007), making it a less 'idyll' place to live in. Moreover, congestion problems are no more exclusively present at urban surroundings. Therefore, for instance, car lovers seeking for green and peaceful neighbourhoods will mostly be rather dissatisfied with their chosen rural neighbourhood.

An alternative explanation for the low residential satisfaction of rural residents is that these people might have been forced to live in these neighbourhoods due to budget restraints. According to Meeus and De Decker (2013) and Van Asche et al. (2008) a lot of people who moved from the city to more rural neighbourhoods indicate that they did not really wanted 
to leave the city, but that rising dwelling prices (due to gentrification processes) forced them to live outside the city in order to live in a dwelling of their needs.

The 'Spatial Structure Plan for Flanders', the present structure plan (ratified in 1997 by the Flemish government) that gives a vision of the desired future spatial structure of Flanders, tries to restrict further urban sprawl by introducing a more active oriented form of planning. The most important spatial principle in this plan is called 'deconcentrated clustering', suggesting that residential areas, industrial areas and other kinds of activities need to be clustered in cities and town centres ('clustering'), taking in account the existing dispersed land use pattern ('deconcentrated') (Albrechts et al., 2003; Scheers, 2006). In order to realise this goal, this plan limits the amount of additional dwellings permitted to build in countryside municipalities to maximum $40 \%$. The 'Spatial Structure Plan for Flanders' strives for at least $60 \%$ of additional dwellings in urban areas (Ministerie van de Vlaamse Gemeenschap, 1997). However, this $60 / 40$ relation almost equals the present distribution of Flemings in urban versus rural municipalities (i.e., 58.4/41.6) (http://www.statbel.fgov.be; Ministerie van de Vlaamse Gemeenschap, 2011). The execution of this regulation will consequently not lead to a reduction of urban sprawl, but only to a status quo of the present, undesired situation. Besides, the tools provided to achieve this goal are rather weak: the promotion of residential development is done by designating additional construction land for housing in urban municipalities, but there is no tool to slow down residential development in rural municipalities (e.g., by converting it into protected open space) (Boussauw et al., 2012). An increase in the relation between additional dwellings in 
urban/rural municipalities is necessary in order to cluster activities in urban environments and diminish urban sprawl. ${ }^{6}$

The use of Transferable Development Rights (TDR), a spatial planning tool originated from Northern America, giving the opportunity to transfer development rights from an area where development is undesired (e.g., countryside) to an area where development is more feasible (e.g., urban environments) could be an interesting tool to slow down the undesired residential development in rural areas (Johnston \& Madison, 1997; Kaplowitz et al., 2008; Levinson, 1997; McConnell et al., 2006; Mills, 1980). TDR could give solace for Flemish prospective residential areas in rural municipalities which are not built-up due to an overestimation of the population growth in the nineteen sixties and seventies. A compensation for not building on these areas, financially or physically (by giving the opportunity to build upon land in urban environments), can prevent a further damage of the countryside. These prospective residential areas, which are not built-up yet, can be converted into areas with other destinations (e.g., nature), with the help of spatial implementation plans ('Ruimtelijke UitvoeringsPlannen' in Dutch, or RUPs) (De Vos \& Witlox, 2013).

More people living in urban environments and restricting urban sprawl is not only beneficial for peoples' residential satisfaction, but also for a more sustainable travel behaviour (reducing greenhouse gas emissions and congestion) - due to shorter distances and a higher use of car alternatives (Cervero \& Kockelman, 1997; Ewing et al., 2008; Gonzalez, 2005) - a

\footnotetext{
${ }^{6}$ According to Weitz and Moore (1998), compact development implies that at least $75 \%$ of new housing should be built within urban areas.
} 
higher ecological sustainability (Alberti \& Marzluff, 2004; Ewing, 1997), and a better public health (Booth et al., 2005; Ewing et al., 2003; Lopez, 2004). Obviously, rural residents must be willing to relocate to urban neighbourhoods. Since neighbourhood satisfaction of rural residents is low, and neighbourhood satisfaction is negatively correlated with residential mobility (Oh, 2003; Speare, 1974), rural residents will probably have a rather high intention to move to other locations, such as urban neighbourhoods. Improving the proximity of amenities in urban neighbourhoods - by increasing density and diversity (based on principles such as Compact City, New Urbanism and Transit-Oriented Development) - can then help to increase urbanites' neighbourhood satisfaction, as results indicate that proximity falls short of the urbanites' expectations. This might result in urban residents being (more) satisfied with their residential location and will consequently result in urbanites having a low intention to move to other - more suburban-style - neighbourhoods.

\section{Conclusion}

It seems that a far-developed urban sprawl in Flanders has contributed to the conversion of rural environments from cherished residential places into places where inhabitants are rather dissatisfied. Open spaces, quietness and green areas, reasons why people deserted cities since the nineteenth century, are now aspects that are lacking in the Flemish countryside. Furthermore, rural residents are less satisfied with safety aspects, interaction with neighbours and the composition of the neighbourhood's residents. More immigrants and former urbanites moving to rural municipalities, together with (functional) urbanisation might consequently have contributed to this low neighbourhood satisfaction of rural residents (see also Meeus \& De Decker, 2013). A situation of rural preference has switched 
into one of urban preference, at the expense of a sustainable spatial planning. It seems that, in situations of good accessibility of the countryside (partly after the introduction of the railway and especially after the introduction of the car) and a lack of urban sprawl (availability of green, open spaces in rural environments) neighbourhood preferences are rather balanced. However, a well-developed urban sprawl can bring this equilibrium out of balance. The absence of typical aspects of rural neighbourhoods (e.g., quietness and green areas) brings along urban preferences, just as the overpopulation of cities in the nineteenth century, cancelling out the typical urban aspects (e.g., proximity of facilities), brought along rural preferences. In order to maximise neighbourhood satisfaction, especially for individuals with rural preferences, it is important to restrict further urban sprawl by spatial planning regulations. The contrast between city and countryside has to increase, especially in diffuse regions, like Flanders. This will not only increase neighbourhood satisfaction of rural residents (since preferred neighbourhood aspects will be present in their neighbourhood), it will also lead to more ecological sustainability and a sustainable travel behaviour.

As the dispersed Flemish land use pattern might clearly differ from land use patterns in other regions - e.g., regions clustering activities in urban areas - it might be useful for future studies to compare residential preferences and satisfaction of urban and rural residents in different types of regions. Doing so, this might provide additional information on how strong the effect of the built environment on residential preferences and satisfaction is. 


\section{References}

Adams, Richard E. (1992). Is happiness a home in the suburbs? The influence of urban versus suburban neighborhoods on psychological health. Journal of Community Psychology 20 (4), 353-371.

Alberti, Marina, \& Marzluff, John M. (2004). Ecological resilience in urban ecosystems: Linking urban patterns to human and ecological functions. Urban ecosystems 7 (3), 241-265. Albrechts, Louis (1999). Planners as catalysts and initiators of change. The new structure plan for Flanders. European Planning Studies 7 (5), 587-603.

Albrechts, Louis, Healey, Patsy, \& Kunzmann, Klaus R. (2003). Strategic spatial planning and regional governance in Europe. Journal of the American Planning Association 69 (2), 113129.

Antrop, Marc (2000). Changing patterns in the urbanized countryside of Western Europe. Landscape Ecology 15 (3), 257-270.

Arnberger, Arne, \& Eder, Renate (2011). The influence of green space on community attachment of urban and suburban residents. Urban Forestry and Urban Greening 11 (1), 4149.

Atkinson, Rowland, \& Bridge, Gary (2005). Gentrification in a global context: the new urban colonialism. London: Routledge.

Bhat, Chandra R. \& Guo, Jessica Y. (2007). A comprehensive analysis of built environment characteristics on household residential choice and auto ownership levels. Transportation Research Part B 41 (5), 506-526. 
Booth, Katie M., Pinkston, Megan M. \& Poston, Walker S. Carlos (2005). Obesity and the built environment. Journal of the American Dietetic Association 105 (5), 110-117.

Bouckaert, Boudewijn, \& De Waele, Tom (2000). Ruimtelijke ordening en stedenbouw in het Vlaamse Gewest. Ghent: Mys \& Breesch.

Bourdieu, Pierre (1984). La Distinction. London: Routledge.

Boussauw, Kobe, Allaert, Georges, \& Witlox, Frank (2012). Colouring inside what lines? Interference of the urban growth boundary and the political-administrative border of Brussels. European Planning Studies 21 (10), 1509-1527.

Brower, Sidney (1996). Good neighborhoods: a study of in-town and suburban residential environments. Westport, CT: Praeger Publishers.

Brueckner, Jan K. (2000). Urban sprawl: diagnosis and remedies. International Regional Science Review 23 (2), 160-171.

Bruegmann, Robert (2008). Point: Sprawl and accessibility. Journal of Transport and Land Use 1 (1), 5-11.

Brun, Jacques, \& Fagnani, Jeanne (1994). Lifestyles and locational choices: trade-offs and compromises: a case-study of middle-class couples living in the Ile-de-France region. Urban Studies 31 (6), 921-934.

Buzar, Stefan, Ogden, Philip, Hall, Ray, Haas, Annegret, Kabisch, Sigrun, \& Steinführer, Annett (2007). Splintering urban populations: emergent landscapes of reurbanisation in four European cities. Urban Studies 44 (4), 651-677. 
Cervero, Robert, \& Kockelman, Kara (1997). Travel demand and the 3Ds: density, diversity and design. Transportation 23 (4), 373-394.

Davoudi, Simin, \& Stead, Dominic (2002). Urban-rural relationship: an introduction and brief history. Built Environment 28 (4), 269-277.

De Decker, Pascal (2011). Understanding housing sprawl: the case of Flanders, Belgium. Environment and Planning A 43 (7), 1634-1654.

De Vos, Jonas (2015). The influence of land use and mobility policy on travel behaviour: a comparative case study of Flanders and The Netherlands. Journal of Transport and Land Use $8(1), 171-190$.

De Vos, Jonas, Derudder, Ben, Van Acker, Veronique, \& Witlox, Frank (2012). Reducing car use: changing attitudes or relocating? The influence of residential dissonance on travel behavior. Journal of Transport Geography 22, 1-9.

De Vos, Jonas, \& Witlox, Frank (2013). Transport policy as spatial planning tool; reducing urban sprawl by increasing travel costs and clustering infrastructure and public transportation. Journal of Transport Geography 33, 117-125.

Dieleman, Frans M., Dijst, Martin J., \& Spit, Tejo (1999). Planning the compact city: the Randstad Holland experience. European Planning Studies 7 (5), 605-621.

Dittmar, Hank, Belzer, Dena, \& Autler, Gerald (2004). An introduction into transit-oriented development. In Dittmar, Hank, \& Ohland, Gloria, editors, The new transit town: best practices in transit-oriented development. Washington D.C.: Island Press, 1-18. 
Ellis, Christopher D., Lee, Sang-Woo, \& Kweon, Byoung-Suk (2006). Retail land use, neighborhood satisfaction and the urban forest: an investigation into the moderating and mediating effects of trees and shrubs. Landscape and Urban Planning 74 (1), 70-78.

Ewing, Reid (1997). Is Los Angeles-style sprawl desirable? Journal of the American Planning Association 63 (1), 107-126.

Ewing, Reid, Bartholomew, Keith, Winkelman, Steve, Walters, Jerry, \& Chen, Don (2008). Growing Cooler: The Evidence on Urban Development and Climate Change. Washington D.C.: Urban Land Institute.

Ewing, Reid, Schmid, Tom, Killingsworth, Richard, Zlot, Amy, \& Raudenbusch, Stephen (2003). Relationship between urban sprawl and physical activity, obesity, and morbidity. American Journal of Health Promotion 18 (1), 47-57.

Farrell, Susan J., Aubry, Tim, \& Coulombe, Daniel (2004). Neighborhoods and neighbors: do they contribute to personal well-being? Journal of Community Psychology 32 (1), 9-25.

Fishman, Robert (1989). Bourgeois Utopias: The Rise and Fall of Suburbia. New York: Basic Books.

Gillham, Oliver (2002). The limitless city. A primer on the urban sprawl debate. Washington D.C.: Island Press.

Glaeser, Edward, \& Kahn, Matthew (2004). Sprawl and Urban Growth. In Henderson, Vernon J., \& Thisse, Jacques-Francois, editors, Handbook of Urban and Regional Economics: Vol. 4. Oxford: Oxford University Press, 2481-2527.

Gonzalez, George A. (2005). Urban sprawl, global warming and the limits of ecological modernization. Environmental politics 14 (3), 344-362. 
Groves, Robert M. (1989). Survey errors and survey costs. New York: John Wiley and Sons.

Halfacree, Keith H. (1995). Talking about rurality: Social representations of the rural as expressed by residents of six English parishes. Journal of Rural Studies 11 (1), 1-20.

Handy, Susan, Cao, Jason, \& Mokhtarian, Patricia L. (2005). Correlation or causality between the built environment and travel behavior? Evidence from Northern California. Transportation Research Part D 10 (6), 427-444.

Handy, Susan, Sallis, James F., Weber, Deanne, Maibach, Ed, \& Hollander, Marla (2008). Is support for traditionally designed communities growing? Evidence from two national surveys. Journal of the American Planning Association 74 (2) 209-221.

Heijs, Wim, Carton, Marleen, Smeets, Jos, \& Van Gemert, Angelique (2009). The labyrinth of life-styles. Journal of Housing and the Built Environment 24 (3), 347-356.

Hesse, Markus, \& Scheiner, Joachim (2009). Residential location, mobility and the city: mediating and reproducing social inequity. In Ohnmacht, Timo, Maksim, Hanja, \& Bergman, Manfred Max, editors, Mobilities and Inequality. Farnham, Surrey: Ashgate, 187-206.

Howard, Ebenezer (1902). Garden cities of tomorrow, $2^{\text {nd }}$ edition. London: Sonnenschein \& co.

Johnston, Robert A., \& Madison, Mary E. (1997). From land marks to landscapes: a review of current practices in the transfer of development rights. Journal of American Planning Association 63 (3), 365-378.

Kabisch, Nadja, Haase, Dagmar, \& Haase, Annegret (2010). Evolving Reurbanisation? Spatiotemporal dynamics as exemplified by the East German city of Leipzig. Urban Studies 47 (5), 967-990. 
Kaplowitz, Michael D., Machemer, Patricia, \& Pruetz, Rick (2008). Planners' experiences in managing growth using transferable development rights (TDR) in the United States. Land Use Policy 25 (3), 378-387.

Kasarda, John D., \& Janowitz, Morris (1974). Community attachment in mass society. American Sociological Review 39 (3), 328-339.

Kearney, Anne R. (2006). Residential development patterns and neighborhood satisfaction: impacts of density and nearby nature. Environment and Behavior 38 (1), 112-139.

Kesteloot, Christian, \& De Maesschalk, Filip (2001). Anti-urbanism in Flanders: the political and social consequences of a spatial class struggle strategy. Belgeo 1-2, 41-62.

Kipnis, Baruch A. (2004). Lifestyle studies - An editorial introduction. Geography Research Forum 24, 1-20

Lee, Sang-Woo, Ellis, Christopher D., Kweon, Byoung-Suk, \& Hong, Sung-Kwon (2008). Relationship between landscape structure and neighborhood satisfaction in urbanized areas. Landscape and Urban Planning 85 (1), 60-70.

Levinson, Arik (1997). Why oppose TDRs? Transferable development rights can increase overall development. Regional Science and Urban Economics 27 (3), 283-296.

Lopez, Russ (2004). Urban sprawl and risk for being overweight or obese. American Journal of Public Health 94 (9), 1574-1579.

Lovejoy, Kristin, Handy, Susan, \& Mokhtarian, Patricia L. (2010). Neighborhood satisfaction in suburban versus traditional environments: an evaluation of contributing characteristics in eight California neighborhoods. Landscape and Urban Planning 97 (1), 37-48. 
McConnell, Virginia, Walls, Margaret, \& Kopits, Elizabeth (2006). Zoning, TDRs and the density of development. Journal of Urban Economics 59 (3), 440-457.

McDowell, Linda (1997). The new service class: housing, consumption, and lifestyle among London bankers in the 1990s. Environment and Planning A 29 (11), 2061-2078.

Meeus, Bruno, \& De Decker, Pascal (2013). De geest van suburbia. Antwerpen-Apeldoorn: Garant.

Milgram, Stanley (1970). The experience of living in cities. Science 167, 1461-1468.

Mills, David E. (1980). Transferable development rights markets. Journal of Urban Economics $7(1), 63-74$.

Ministerie van de Vlaamse Gemeenschap (1997). Ruimtelijk Structuurplan Vlaanderen. Brussels: Ministry of the Flemish Community.

Ministerie van de Vlaamse Gemeenschap (2011). Ruimtelijk Structuurplan Vlaanderen, coordinated version 2011. Brussels: Ministry of the Flemish Community.

Munters, Quirinus J. (1992). Bestaan leefstijlen (nog) wel? Sociologische Gids 39, 179-185.

Myers, Dowell, \& Gearin, Elizabeth (2001). Current preferences and future demand for denser residential environments. Housing Policy Debate 12 (4), 633-659.

Newman, Peter (1992). The Compact City: an Australian perspective. Built Environment 18 (4), 285-300.

Newman, Peter, \& Kenworthy, Jeffrey R. (1996). The land use-transport connection: An overview. Land Use Policy 13 (1), 1-22. 
Oh, Joong-Hwan (2003). Social bonds and the migration intentions of elderly urban residents: The mediating effect of residential satisfaction. Population Research and Policy Review 22 (2), 127-146.

Parkes, Alison, Kearns, Ade, \& Atkinson, Rowland (2002). What makes people dissatisfied with their neighborhoods? Urban Studies 39 (13), 2413-2438.

Patacchini, Eleonora, \& Zenou, Yves (2009). Urban sprawl in Europe. Brookings-Warton Papers on Urban Affairs 125-149.

Pisman, Ann, Allaert, Georges, \& Lombaerde, Piet (2011). Urban and suburban lifestyles and residential preferences in a highly urbanized society. Belgeo 1-2, 89-104.

Sampson, Robert J. (1991). Linking the micro- and macrolevel dimensions of community social organization. Social Forces 70 (1), 43-64.

Scheers, Joris (2006). Spatial planning in the economic core of Europe: The transition from land use planning to spatial structure planning in Flanders. In Adams, Neil, Alden, Jeremy, \& Harris, Neil, editors, Regional Development and Spatial Planning in an Enlarged European Union. Aldershot: Ashgate, 65-86.

Schuermans, Nick, Meeus, Bruno, \& De Decker, Pascal (2014). Geographies of whiteness and wealth: white, middle class discourses on segregation and social mix in Flanders, Belgium. Journal of Urban Affairs 37 (4), 478-495.

Seo, J-K. (2002). Re-urbanisation in regenerated areas of Manchester and Glasgow. New residents and the problems of sustainability. Cities 19 (2), 113-121.

Short, John (1991). Imagined Country. London: Routledge. 
Smith, Darren (2007). The changing faces of rural populations: “(re) Fixing” the gaze' or 'eyes wide shut'? Journal of Rural Studies 23 (3), 275-282.

Speare, Alden (1974). Residential satisfaction as an intervening variable in residential mobility. Demography 11 (2), 173-188.

Talen, Emily (2001). Traditional urbanism meets residential affluence. An analysis of the variability of suburban preference. Journal of the American Planning Association 67 (2), 199216.

Tonnies, Ferdinand (1963). Community and society. New York: Harper and Row.

Torra, Vicenc, Domingo-Ferrer, Josep, Mateo-Sanz, Josep M., \& Ng, Michael (2006). Regression for ordinal variables without underlying continuous variables. Information Sciences $176(4), 465-474$.

Van Acker, Veronique (2010). Spatial and social variations in travel behaviour: incorporating lifestyles and attitudes into travel behaviour-land use interaction research. Doctoral dissertation, Ghent University.

Van Acker, Veronique, Mokhtarian, Patricia L., \& Witlox, Frank (2011). Going soft: on how subjective variables explain modal choices for leisure travel. European Journal of Transport and Infrastructure Research 11 (2), 115-146.

Van Acker, Veronique, Mokhtarian, Patricia L., \& Witlox, Frank. (2014). Car availability explained by the structural relationships between lifestyles, residential location, and underlying residential and travel attitudes. Transport Policy 35, 88-99. 
Van Asche, Jo, Janssens, Herman, \& Reynaert, Herwig (2008). Resultaten van de analyse van de woonnoden van 20 doelgroepen in drie deelruimten van de stad Gent in 2008. Studie in opdracht van Stad Gent.

van Ham, Maarten, \& Feijten, Peteke (2008). Who wants to leave the neighbourhood? The effect of being different from the neighbourhood population on wishes to move. Environment and Planning A 40 (5), 1151-1170.

van Wee, Bert (2009). Self-selection: a key to a better understanding of location choices, travel behaviour and transport externalities? Transport Reviews 29 (3), 279-292.

Verhetsel, Ann, Thomas, Isabelle, \& Beelen, Marjan (2010) Commuting in Belgian metropolitan areas. The power of the Alonso-Muth model. Journal of Transport and Land Use $2(3 / 4), 109-131$.

Verhetsel, Ann, \& Witlox, Frank (2006). Children and housing: 'Only the best is good enough'. Some evidence from Belgium. Childhood. A Global Journal of Child Research 13 (2), 205-224.

Weber, Max (1972). Wirtschaft und Gesellschaft. Tübingen: Mohr.

Weitz, Jerry, \& Moore, Terry (1998). Development inside urban growth boundaries: Oregon's empirical evidence of contiguous urban form. Journal of the American Planning Association 64 (4), 424-440.

Williams, Katie (2004). Reducing Sprawl and Delivering an Urban Renaissance in England: Are These Aims Possible Given Current Attitudes to Urban Living? In Richardson, Harry W., \& Bae, Chang-Hee C., editors, Urban sprawl in Western Europe and the United States, Aldershot: Ashgate, 37-54. 
Wirth, Louis (1938). Urbanism as a way of life. The American Journal of Sociology 44 (1), 1-

24.

AErø, Thorkild (2006). Residential choice from a lifestyle perspective. Housing, Theory and Society 23 (2), 109-130.

\section{Appendix}

Travel mode preferences were retained based on 118 variables on opinions and habits concerning leisure locations and mobility. In order to obtain factors that unambiguously reflect travel mode preferences, it was necessary to factor analyze the obtained (first-order) factors (second order factor analysis) (De Vos et al., 2012).

Pattern matrix of the second-order factor analysis of travel mode preferences

\begin{tabular}{lcc}
\hline & Second-order factor $\rightarrow$ & Pro car \\
First-order factor $\downarrow$ & alternatives & Pro car \\
\hline Accessibility public transit & 0.822 \\
Pro public transit & 0.603 \\
Accessibility bicycling/walking & 0.467 \\
Proximity of shops, bars, ... & 0.411 \\
Pro bicycling/walking & 0.316 & \\
\hline Environmentally aware & & 0.908 \\
Pro car & & 0.642 \\
\hline
\end{tabular}

